\title{
Nineteenth-Century Eurasians and Spatiality in Emma Roberts' Scenes and Characteristics of Hindostan, with Sketches of Anglo-Indian Society (1835)
}

\author{
Divya A \\ Assistant Professor, Department of Humanities and Social Sciences, Indian Institute of \\ Technology Madras, Chennai, India. ORCID: oooo-0oo2-4516-6763. \\ Email id divya@iitm.ac.in
}

\begin{abstract}
In this article, through a spatial reading of Roberts' Scenes and Characteristics I illustrate how the stringent regulations of the East Indian Company disempowering the Eurasians are manifested through the spatial strictures, and how notions of cultural purity and hierarchy are realized through the politics of space in colonial India. Spatial concepts of lived space, third space, and hybridity - drawn from the theories of Homi Bhabha, Edward Soja and Henry Lefebvre-are useful in mapping the spatial politics in nineteenth-century India, especially in relation to the Government-house in Calcutta, the seat of the highest authority in colonial India, and the marginalized orphanages/schools run by the East India Company primarily for the benefit of Eurasian children. Discrimination through spatially segregation was practiced by the British East India Company in order to preserve the racial purity of the European upper class at the helm of the Indian colony. My paper illustrates how the fortunes of the male and female "half-castes" of empire were variously charted, and how spatial homogeneity was subverted through the subtext of marital relations. The "third space" that some of the fortunately-marked interracial men and women occupy constantly pulled at the seams of apparently inviolable concepts of homogeneity and purity to expose and challenge the cultural dominion of the British Empire.
\end{abstract}

Keywords: Eurasian, spatiality, Bhabha, Soja, Government-house, Lefebvre, third space, colonialism, East India Company, orphan.

\section{Introduction}

Emma Roberts' (1835) short introductory note to her first of her three volume travelogue series Scenes and Characteristics of Hindostan states that the work appeared first as "a series of papers" in the Asiatic Journal and proved to be immensely popular both in Britain and India in the nineteenth centuryi. It was perceived as "light literature-a guidebook for tourists who seek the picturesque, and for Anglo-Indians, especially women who wish to escape the tedium and entrapment of colonial life" (Ross, 2003, p. 528). In the introduction Roberts (1835) herself modestly points to the work's socio-spatial insights as the rationale behind its success: the new awakening of curiosity, interest and attention towards British colonies in the Eastern world has made any work that offered an insight into the "subject of Native and Anglo-Indian Society...generally acceptable" to the English reading public. While the word "native" is transparent in meaning in its reference to the original inhabitants of the colony, the hyphenated term "Anglo-Indian" is used by Roberts to signify the Europeans residing in colonial India. The introduction projects the safe assumption that racial

(c) AesthetixMS 2020. This Open Access article is published under a Creative Commons Attribution Non-Commercial 4.0 International License (http://creativecommons.org/licenses/by-nc/4.o/), which permits non-commercial re-use, distribution, and reproduction in any medium, provided the original work is properly cited. For citation use the DOI. For commercial re-use, please contact editor@rupkatha.com. 
divisions and demarcations of hierarchy are distinct and uncomplicated in this British colony in the nineteenth century.

The natives of the orient are of obvious ethnographic curiosity for the reading public, and the spatial, economic, and "domestic manners of British colonialists" in India were also clearly becoming a subject of "human interest" to British migrants whose numbers were gradually increasing in the nineteenth century (Gibson \& Rudy, 2015, p. 190). The reference to the interracial community born out of the mixing of two cultures, the union between European fathers and Indian mothers-variously labelled as Eurasians, Indo-Britons, Country-born-is carefully elided in the introduction to the Scenes and Characteristics of Hindostan. Though Roberts refrains from drawing attention to her insightful and poignant sketches into the apparently tainted lives and fortunes of the Eurasians, as a topic of cultural curiosity and significance for readers, Roberts' travelogue does inexorably contain snapshots of their trials, anxieties, disappointments, unique discriminations as wells as their triumphs incisively if not at great length in her volumes.

In this article, through a spatial reading of Roberts' Scenes and Characteristics I illustrate how the stringent regulations of the East Indian Company disempowering the Eurasians are manifested through the spatial strictures, and how notions of cultural purity and hierarchy are realized through the politics of space in colonial India. In terms of terminology, Roberts uses the word Anglo-Indian to denote the Europeans in India, contrary to its current meaning, and I follow Roberts's use of terms to refer to the racial groups: "Anglo-Indians" for Europeans; and "Eurasians" and "Indo-Britons" to refer to the mixed-race population. If commercial aspirations and security led to East India Company's encouragement of Europeans to intermarry with the natives in the seventeenth century and early eighteenth century, a perceived threat to its authority and racial supremacy impelled them to control the burgeoning population of Eurasians in the late eighteenth century and nineteenth century. The Calcutta Chronicle in 1792 contains a cautionary tale for the Company about the interracial population: "If forthwith drastic measures are not put into operation to keep down the East Indian [Eurasian] race, they will do to the British in India what the Mulattoes have done to the Spaniards in San Domingo" (Stark, 1934, p. 18-19). What is evident in this warning publicized in the Chronicle is the dreaded anticipation of the betrayal of pure-blooded patricians and their dominance in the status quo by the inferior mixed ethnic community.

The East India Company strove to contain and abandon the Eurasians in specific, marked and less powerful spatialities through its key and most debilitating regulation regarding marital relations between Europeans and Eurasian/Indian women. Deploying theories of spatiality, I map the Company's policy of discrimination of the Eurasian community through a study of two key structures in Calcutta that occupy different ends of the power spectrum: the Government-house and the orphanages. Tracing the fault lines in the power relations between the dominant and suppressed races, I demonstrate how some of the "dark-eyed" and beautiful "half-caste" women are able to gain physical access to the House of power through marriage, even as the regulatory space of the orphanage exerts a more controlling and confining grasp of the Eurasian women's marital prospects.

\section{Spatial Politics of the Government-house}

Roberts (1835) declares that gaining admittance to socio-spatial sphere of the Government-house in Calcutta was "the grand test of gentility in India" (p. 54). She notes that even wealthy Europeans whose "occupation and calling" (p. 54) were unsuitable did not get invited for the social gatherings held in the governor's house. Though invitations to such socializations within spaces of influence 
and authority always already involved only people from the superior ranks in society, the exclusions of wealthy Europeans reflected Britain's own entrenched and traditional attitudes towards class that continued to favour nobility of birth over wealth acquired through trade. Thus, racial inferiority - of the Eurasian community born out of "miscegenation" - and class inferiority were used as identifying traits by the East India Company in an attempt to secure the space of the highest authority only for the untainted class and race, and concomitantly demarcate and consolidate several distinct identities for the inferior others with varying degrees of social power/lessness outside the spatiality of power.

Discussing the rational for the refusal of entry for the mixed population, Roberts significantly and conveniently points the finger of blame at the "native prejudice" as shaping the East India Company's policy of exclusion of the Eurasians from the spatiality of the Governmenthouse. She states that the natives "look down, or at least have looked down, with great contempt upon a mixed breed, which, upon the maternal side must have sprung from the lowest or the least virtuous class of society" (Roberts, 1835, p. 95). The word "lowest" in juxtaposition with the phrase that suggests the notion of looking "down" inevitably spatializes the social hierarchy in Indian society during the times of the East India Company. Roberts here internalizes and channels the ideological viewpoint of the Company that insinuates that since the smooth functioning of its administration was made possible through the implicit and explicit collaboration of the higher echelons of native society, the progeny of the union between "outcast females" (p. 95). and European men had to be kept outside the realms of power, influence, and affluence in order to appease, and continue to receive the cooperation of the higher caste and class of natives.

For the British who sought to preserve the racial superiority of the ruler-administrators at the helm of the Empire were largely compelled to do so due to their apprehensions about the rise of a hybrid population stemming from relations with the native women predominantly from the lowest classes. The Company however utilized the local tradition of caste prejudice to simultaneously conceal and practice their own discriminatory attitudes and policies towards Eurasians. It is to be noted that the Company's perception of unsuitability of certain classes of Europeans for the higher offices in the East Indian Company also stemmed from the fact that many poor European men married native and Eurasian women (Hawes, 1996, p.114).

Therefore, as the Eurasians were apparently polluted from their mother's social and cultural heritage, they were barred from the Government-house despite their "unsullied descent from European parents"(Roberts, 1835, p. 95).In such a context, the derogatory terms "half-caste" and "eight annas" meaning half of a rupee (a local monetary denomination) (Tweedie,1998, p. 65) underline the idea of incomplete identities for Eurasians, signifying an interconnectedness between lower social and economic status in the choice of terminology drawn from the local discriminatory systems embedded within native cultural traditions. The assumption here is that it is the mother's blood that corrupts what is ideologically considered to be "unsullied descent" of the European paternal heritage.

The argument put forth by Roberts in Scenes and Characteristics of Hindostan is an instance of what Lionel Caplan (2000) calls "common British practice" (p. 867) to craftily rationalize the elimination of Eurasians from the power structures within the company regime. However, even a cursory glance at the policies of the East India Company in the social, personal and professional spheres of the Eurasian community will illuminate the extent of the Company's ruthless and systemic attempt at racial discrimination and consequent spatial isolation of the interracial population, clearly suggesting that the Eurasian exclusion arises primarily from a fear of the métis populace, not an indulgence of native predilections about the caste purity of the rulers. Roberts 
(1835) herself sharply points out the disadvantages for the pure Europeans of their social and spatial proximity with the Eurasians:

To be seen in public with, or known to be intimate at the houses of Indo-Britons, was fatal to a new arrival in Calcutta; there was no possibility of emerging from the shade, of making friends or connections in a higher sphere. (p. 95).

Roberts's pointed language underlines the contaminated spatiality of the Eurasians. Even to be caught alongside a Eurasian in a street would bode ill for a European seeking to enter the "higher sphere" of the East India Company. The Eurasians who were considered to be "darker than...the natives" are also figuratively linked with the "shade", with darker spatial associations, and consequently lower spatial, social and moral status (Roberts,1835, p. 53).Roberts' words are infused with the metaphor of spatial hierarchy and networks, and implies a concomitant order of social (in)significance and (im)possibilities: the higher sphere indicating higher echelons of European society and the word "shade" indicates the bottom of the social pile from which climbing up the social ladder was impossible. In the domestic sphere, the Europeans were also strongly discouraged from marrying Eurasian women with the threat of ostracization from European community and removal from Company employment. Thus, the Company's stringent regulation attempts to discipline and control the spatial practices of the Eurasians and Europeans in both the public and the domestic spheres with the intention of preserving the racial and cultural boundaries between the Europeans and the others.

\section{Breaking Spatial Barriers.}

Influential ideologies behind spaces can control and limit mobility of people, but the power of spatiality can also be subverted and controlled by the spatial practices of its inhabitants. To evaluate any resistance to the Company's colonial hierarchy that is realized through racial, social and spatial segregation, a mapping of the access to the sphere of the Government-house through theories of spatiality would be pertinent. In The Production of Space by Henry Lefebvre (1991), the idea of the "conceived space" captures the tendencies of the "dominant space in any society" and the term connotesa space theorized and planned by the state, the "urbanists" and "social engineers" in terms of its users, purpose and functions (p. 291). Perceiving the supreme space of power coded in the Government-house in Calcutta through Lefebvre's spatial lens will elicit this space as a manifestation of the "conceived space" due toits system of regulations in place for inclusion and exclusions of persons on the basis of race and class. Discussing Lefebvre, Edward Soja (1996) states that "mental spaces are...the representation of power and ideology, of control and surveillance" (p. 67). However, slightly reformulating Lefebvre's "conceived space" as "the second space", Soja (1996) states that while the "mental space" does possess its detractions and limitations, there are also possibilities for "utopian thought and vision" within it (p. 67). However, in the case of the Government-house in Calcutta in nineteenth-century India, there is no apparent and conceivable utopian "thought and vision" embedded in this colonial administrative space. Instead, what is ostensible is a normative blueprint of the East India Company's modus operandi with regard to its administration that manipulated spatial access to its structures to sustain its authority over the colonialised people and their landscape.

Perceiving the Government house through the notions of "conceived space" and "second space" usefully illuminates its restrictive regulatory policies. However, the subaltern glimpse that Emma Roberts offers through her Scenes and Characteristics of Hindostan about some of the everyday realities of the Eurasians and their private sphere provides a subversive window into the 
workings within the Government-house in Calcutta. The domestic practices of the Eurasians in relation to the site of power exemplify spatial perspectives that Lefebvre describes as "lived space", and Soja and Bhabhaas "third space". "Lived space" for Lefebvre (1991) is the space of the "users" and "inhabitants" of a space (p. 39). In between the notion of the conceived space of who should be invited and debarred from this power house in Calcutta, and the perceptual spatiality, that is the actuality, of the physical movement of bodies in this space is the lived reality of the people navigating the corridors of power. Lefebvre's "lived space" that exists between the theory and the perception relates to one of experiential practicality and the physicality and subjectivity of the people traversing the spatiality of power. This spatial concept is useful to map the nature of the identities and the purpose of the Eurasians moving within the space of the Government-house in Calcutta in nineteenth-century India.

In fact, the spatial practices of the users of the Government-house are crucial to the creation of the dominant identity of the place. Reginald Heber, the Bishop of Calcutta, is thought to have opined that the Government-house "has narrowly missed being a noble structure" (Roberts, 1835 , p. 69). Its architectural design is apparently deficient in terms of the number of floors and porticos, and the nature of its colonnades is considered by Bishop Heber to be "paltry" (Roberts, 1835). Despite being the official residence of the highest British authority in India at the time, this "Asiatic" residence was considered not to adequately reflect the architectural characteristics associated with the structures of the British nobility (Roberts, 1835). Yet, for Roberts there is one important phenomenon that redeems the grandeur and the glory of the Government-house: the presence of "gay parties of visitors, ladies in ball-dresses, and gentlemen in full-uniform" ambling within its apparently depressing interiors (p. 72).

It is the presence of the guests attired in superior European outfits, especially the ladies in ball dresses that establishes the aura of power and dignity of the Government-house. Roberts' remark underscores the concept that the practices of the inhabitants within a space are key performative elements that aids in the orchestration and consolidation of the identity of a particular spatiality. While access to a space entails particular practice, it is such a performance that creates the spatial identity. Such an understanding of spatial dynamics is also significant in exposing the particularities of the politics of colonization. The spatial practice of the Europeans within significant and symbolic structures of power, not only with regard to political administration, but also vis-à-vis socializations and inflections of domesticity within such hierarchical spaces on the colonial landscape, establishes and consolidates the primacy and supremacy of the colonialists.

\section{The "charms of the dark-eyed beauties".}

Read through this framework of spatiality and power the beautiful "dark-eyed" half-caste "beauties" who surprisingly gain entrance to the heavily guarded Government-house clearly subvert the stringent policies of the East India Company (Roberts, 1835, p. 96). Their access to this administrative structure springs from the power of the private sphere to disturb, or to reorient, the equilibrium of the public sphere. Thus, despite the fact that the Europeans were threatened with banishment from higher spheres in society, and exclusion from positions of power if they married Eurasian women, Roberts (1835) states that some of the Europeans did succumb to the "charms" of the "dark-eyed" Eurasian women and married them. When a European high-ranking official marries a Eurasian woman, its social consequence is his contrivance to bring his wife into the Government -house for social occasions. His wife accordingly sets a precedent for the admittance of other married Eurasian ladies to enter the portals of power. Roberts (1835) writes with some degree of 
astonishment at the fact that even the illegitimate daughters, whom "Several succeeding Governors-general positively refused to admit" into the Government-house somehow managed to gain entrance into the space of power (P. 97). The phrase "somehow" hints at and camouflages the power of their charms in winning over the affections of the men who court them into marrying and eventually gaining them admission to a spatiality of power that had hitherto kept the hybrid bodies outside its confines.

Though Roberts does not clearly state the economical position of these Eurasian women who cross the threshold of the Government-house in the 1830s, it can be safely assumed that they are daughters of men of wealth and influence in society. These women are those who could have been "fortunate ...to possess relatives in a certain rank in society" (Roberts, 1835, p. 32), and as a result are better educated, offered access to socializing, which might result in marriage, with highranking European men. The personal attractions of these Eurasian women are employed in, and prove beneficial, in the process of the subversion of the boundaries of race and class that compartmentalized Eurasian communities in order to disempower them. The acts of these Eurasian women and European men triumphantly, albeit momentarily in the 1830 , create an alternative space within the Government-house through their spatio-social practices.

This "space" occupied by the European men and Eurasian women in the Government-house can be termed, in Lefebvre's words, as "lived space” or practiced space, and resembles Soja's (1996) idea of the "third space" as the notion translates the existing dualities of what he terms the first and second space - the physical and the mental space - to create:

a critical "other-than" choice that speaks and critiques through its otherness...It does not derive dimply from an additive combination of its binary antecedents but rather from a disordering, deconstruction, and tentative reconstitution of their presumed totalization producing an open alternative that is both similar and strikingly different". (p. 61)

This "third space" illuminates the nature of the space occupied by the Eurasians in colonial India, who by their very presence constantly "disorder", "deconstruct" and "reconstitute" the totalities assumed by the Europeans. The Eurasian women's physical, social and cultural characteristic of being "similar" yet "different" from European women performs the function of eroding the homogeneous cultural purity and superiority of racial systems within power structures such as the Government-house.

Soja's assertion that his conception of "the third space" is not the resultant position of "binary" originaries further inevitably evokes Homi Bhabha's theoretical concept of Third Space. Bhabha, clarifying his perception of hybridity, states that "the importance of hybridity is not to be able to trace two original moments from which the third emerges, rather hybridity...is the "Third Space" which enables other positions to emerge" (Rutherford, 1990, p.211). He offers hybridity and third space as an interstitial or in-between space that creates "new signs of identity and innovative sites of collaboration and contestation" (Bhabha, 1994, p.2).

These ideas of "lived" and "third" space that together suggest the presence of active negotiation of meaning, identity, contestation, subversion, and collaboration can be seen at work through the presence of the Eurasian women within the spatiality of the Government-house in Calcutta. Roberts however poignantly points out that "These young ladies form the only individuals of their sex who enjoy greater privileges than are allowed to the masculine portion of the same class" (Roberts, 1835, p. 97). For the Eurasian women, the omnipresent patriarchal ideology embedded within European society offered the "dark-eyed beauties" certain inadvertent advantages. The British East India Company, considered the Eurasian women "the weaker sex" in 
comparison with the Eurasian men, and therefore less of a political and economic threat to the dominant position of the pure-blooded European patricians. Thus, a certain section of the mixed breed women were allowed the privilege of endowing themselves with skills and attributes that has the unintended consequence of equipping them to breach supposedly inviolable boundaries, including that of the Government-house that protect European cultural and social hegemony.

This policy of dividing and managing the Eurasian men and women informs the academic structure of the schools of the East India Company. The Eurasian daughters are taught valuable skills, including dancing, something which is beyond the purview of Eurasian sons, and as a result the "young ladies, conscious of their superior prospects, look down upon their male relatives with undisguised disdain" (Roberts, 1835, p. 97). It is obvious that the divisive policies of the East India Company had a percolating but socially pernicious and dysfunctional effect even on familial bonds within the Eurasian community. While the women "aspire" to win European men in marriage, the Eurasian men, who are in occupations that are marked by powerlessness and inferior status, marry within the interracialii. Roberts importantly points out that these men refrain from seeking European women because of their anxiety that they would be "despised by their (European) wives" for their heritage and skin complexion, and hence they safely marry within the Eurasian community(Roberts, 1835, p. 97).A politically-inflected set of attitudes and concerns create social and cultural disjunctions between the men and women of the Eurasian communitydiscriminations that the dominant European company orchestrated to safeguard its supremacy in the Indian colony within the first half of the nineteenth century.

\section{Spatial Confinement and Orphan Schools}

In comparison with the Government-house, the spatiality of the social institution of the orphanage seems to occupy the other, the weaker, end of the power spectrum. However, it is important to understand that the word "orphan" does not have the same meaning then as it does today. Maureen Ivers states that records for the year 1823 show that the Lower Orphan School contained, out of a total of 270 boys and 379 girls, 150 boys and 235 girls whose fathers who were livingiii. The majority of the residents in this institution were clearly not "orphans". The word orphanage therefore was thus a euphemism for schools (McMenamin, 2011, p. 25). In fact, all children of the soldiers and officers of the East India Company-be they European, British, Eurasian, legitimate and illegitimate-were expected to be sent to school at the age of four. Such a measure was intended to keep the military lives of the men unencumbered, and to protect some of the children from destitution and immorality (Hawes, 1996, p.27).

Vyvyen Brendon(2005) records that in 1783 in Calcutta two types of orphanages-the Upper Orphanage and the Lower Orphanage - were established for the Eurasian children of the higher and lower ranks of British officers respectively (p. 44).It is also significant to note that initially "the children of officers occupied the upper floors of the building...while the children of lower ranks moved into the ground floor and the terms Upper and Lower School came into common parlance" (Ghosh, 2006, p. 229).The spatial metaphor used to describe the powerful and powerless sections of society as the "higher" and "lower" ranks in society is literalized in the architecture of the orphanage in its initial phase. Soon the two orphanages were separated and housed in different and distant structures, yet what is of import in terms of their racial demography is that the majority of children in the orphanages were Eurasian with British children as a minority ${ }^{\text {iv }}$ The children of the Eurasians were divided into the two types of schools on the basis of their level of wealth, rank 
and influence in the purview of the East India Company administration. Children of rich British officials and Eurasians were largely sent back to England for education (Anderson, 2011, p. 145).

Roberts in her travelogues is obviously more preoccupied with the prospects of the less fortunate Eurasian women in the Lower Orphan School as it is their plight that is recorded in quick but sharp sketches in her volumes than the fate of those daughters in better, and privately, funded schools. In addition to educating and providing for the girls, the Lower Orphan School also sought to facilitate matches between their wards and the Europeans through the hosting of balls within their walls. In the Regency and early Victorian period, balls were especially the sites for young people to socialize with the intention of falling in love with an eligible partner. In fact, "dance [was] central to the private institution of courtship and marriage" in the period (Engelhardt9). Jane Austen famously wrote in Pride and Prejudice (1853) that "To be fond of dancing is a certain step towards falling in love" $(\mathrm{p}, 6)$. The apparently undesirable side to this romantic perspective was the ballroom's association with depravity: "the very scene in which young, wealthy women were expected to make their debut into the fashionable world was cast in conduct books and moral tracts as dangerous and seething with sin and licentious men" (Engelhardt, 2009, p. 20).

In such a context, with criticism targeted even at the ballroom dancing of the wealthy, it is easy to understand the assumption of impropriety attached to the hosting of balls for the benefit of the girls at the orphanages in colonial India under the regime of the Company. Valerie Anderson records that

By 1820 the upper orphanage European girls (and possibly some of the Eurasians too) were being shipped back to England, the twice monthly balls were discontinued by the 1830 , and the covenanted and commissioned men were actively discouraged from forming relationships with Eurasian women. (p. 187)

Roberts poignantly comments that the resulting effect of the discontinuation of dancing on the school system was its assumption of the "character of a nunnery" (Roberts, 1835, p.33).

With the elimination of the ball-room space from the orphanages, and the freedom to choose from an array of suitors becomes curtailed and disciplined. The spatio-social ritual of meeting, dancing, talking, and deciding is replaced by what Roberts terms a "judicious" but "singular" regulation regarding the marriage of the school's inmates $(1835$, p. 82). If a European man of good character, be it a non-commissioned officer or a private from a regiment, desires to marry a Eurasian girl, his choice of a wife can be made by sight only and on a single occasion. One can immediately perceive the social-cultural space shrink in such an interview. Once he has decided upon the bride the man cannot refuse marriage or change his choice of wife. While the girl has the freedom to reject the proposal of marriage, she can leave the institution only upon her marriage. Roberts comments that a greater number of orphans are spinsters, and "as they are frequently destitute of family connexions... see very little of society, and have comparatively little chance of being well-established" (1835, p.33). The lack of family support for the Eurasian women translates as social and spatial confinement in orphanages.

Stasis is thus evident in this space of the Lower Orphan School, a state that is unleavened by the practical realities of the inmates and visitors. Stringent measures that restrict the physical movement and entertainment of the inmates and guests within the orphan schools transform the institution into a conceptual space, an instrument of the East India Company that suppresses any spatial practice that could subvert the state's policy of protecting the superiority and authority of European upper class and race. In this Lower Orphan School there is no possibility of the emergence 
of the lived or third space that breaks free from spatial and cultural regulations and restraints that confine individual desires and aspirations.

If the presence of guests in ball gowns in the Government-house is the one significant aspect that Roberts believes transforms the largely non-impressive "Asiastic residence" into British residence, the absence of balls turns the Lower Orphan School into a non-British institution culturally as it usurps from young men and women the power and freedom to socialize. For the Eurasians, the restructuring of conceptual spaces becomes possible only at "higher" echelons of a racially superior society. If a section of the Eurasian women can capitalize on their charm and ingress into the Government-house, their "dark-eyed" compatriots in the Lower Orphan School cannot make an egress out of it of their own free will.

\section{Endnotes}

${ }^{\mathrm{i}} \mathrm{i}$ There is no pagination for this introduction in the first volume of Emma Roberts' Scenes and Characteristics of Hindostan(1835).

ii The professions of the boys from the orphan schools run by the East India Company administration included that of fifers, drummers, and apprentices in various departments.

iii Maureen Evers, India L-Archives. http://archiver.rootsweb.ancestry.com/th/read/INDIA/20o901/1232515189

iv Hawes, Poor Relations, p.25. Also, Maureen Evers writes that the children of pure European heritage "could be returned to England, however those returned were virtually all officers' children, or from a later date, occasionally sons of British Army soldiers. India L-Archives.

http://archiver.rootsweb.ancestry.com/th/read/INDIA/2009-01/1232515189.

\section{References}

Anderson, V.E.R. (2011).The Eurasian Problem in Nineteenth Century India [Doctoral dissertation, SOAS (School of Oriental and African Studies)] https://eprints.soas.ac.uk/13525/1/Anderson_3334.pdf

Austen, J. (1853). Pride and Prejudice. Rd Bentley.

Bhabha, H. K. (1994). The Location of Culture. Routledge.

Brendon, V. (2005). Children of the Raj. Phoenix.

Caplan, L. (2000). Iconographies of Anglo-Indian Women: Gender Constructs and Contrasts in a Changing Society. Modern Asian Studies, 34(4), 863-892. https://doi.org/10.1017/s0026749xoooo3784

Engelhardt, M. (2009). Dancing Out of Line: Ballrooms, Ballets, and Mobility in Victorian Fiction and Culture. Ohio University Press.

Ghosh, D. (2006). Sex and the Family in Colonial India: The Making of Empire. Cambridge University Press.

Gibson, M., \& Rudy, J. (2015). Colonial and Imperial Writing. In L. Peterson (Ed.), The Cambridge Companion to Victorian Women's Writing (Cambridge Companions to Literature, pp. 189-205). Cambridge: Cambridge University Press. doi:10.1017/CCO9781107587823.015 
Hawes, C. J. (1996). Poor Relations: The Making of a Eurasian Community in British India, 1773-1833. Routledge.

Lefebvre, H. (1991). The Production of Space (D. Nicholson-Smith, Trans.). Blackwell Publishing. (1991).

McMenamin, D. (2011). The Roots of Anglo-Indian Cultural Practices and Attitudes. International Journal of Anglo-Indian Studies, 11(2), pp. 25-36 https://www.semanticscholar.org/paper/THE-ROOTS-OF-ANGLOINDIAN-CULTURAL-PRACTICES-AND-

McMenamin/1b49145638ac29adgceoo88043577f883aadcebc?p2df

Roberts, E. (1835). Scenes and Characteristics of Hindostan: With Sketches of Anglo-Indian Society (Vols. 1-3). WH Allen and Co.

Ross, D. (2003). [Review of the book Curiosity and the Aesthetics of Travel Writing, 1770-1840:'From an Antique Land' by N. Leask]. Criticism, 45(4), 525-529. 10.1353/crt.2004.0024

Rutherford, J.(Ed.). (1990). The Third Space. Interview with Homi Bhabha. Identity:Community, Culture, Difference. (207-221). Lawrence \& Wishart.

Soja, E. W. (1996). Thirdspace : Journeys to Los Angeles and Other Real-and-Imagined Places. Blackwell Publishing.

Stark, H. A. (1934). John Ricketts and His Times: Being a Narrative Account of Anglo-Indian Affairs During the Eventful Years from 1791-1835. Wilsone \& Son.

Tweedie, J (1998). Hindustani as It Ought to Be Spoken (Romanized).Asian Educational Services. 